\title{
Point Resistance of Piles in Sand
}

\author{
By Norihiko MiURA*
}

(Received July 8, 1983)

\begin{abstract}
Mechanism of point resistance of pile in sand was investigated mainly from the viewpoint of the particle-crushing of sand at the pile tip. It is shown that the work dissipated in the particle-crushing of sand is as large as 66 percent of the total work done by the external force, hence the point resistance of a pile in sand greatly depends on the particle-crushing property of the sand. It is also shown that the relationship between point resistance and vertical pressure of a pile can be predicted from the triaxial compression tests in a particle-crushing region.
\end{abstract}

\section{Introduction}

A number of studies on the pile in sand have been made and thereby suggested that the mechanism of the point resistance of piles closely relates to the particle-crushing of sand around the pile tip. However, relatively few studies had mentioned the effect of particle-crushing of sand on the point resistance of piles. The present study carried out loading tests on a model pile in sand to examine, from the energy balance viewpoint, how the particle-crushing zone develops around the pile tip and how the particlecrushing affects the point resistance of the pile.

\section{Experiments}

\section{(1) Sample tested}

Sand sieved through $2 \mathrm{~mm}$ openings and having following main properties was used for the test: specific gravity $=2.66$, maximum void ratio $=1.07$, minimum void ratio $=0.627$. The grain size distribution of the sand was as shown in Fig. 1. The internal friction angle of the sand was determined to be $46.8 \mathrm{deg}$. in a dense state by a series of drained triaxial compression tests under confining pressures of $100 \mathrm{kPa}$ to $300 \mathrm{kPa}$.

(2) Sand container

Figure 2 shows the schematic diagram of the apparatus used for the pile test. The sand container is an assembly of two pieces of cylindrical walls, a bottom and ceiling plates. The steel model pile is $3.5 \mathrm{~cm}$ in diameter and $33 \mathrm{~cm}$ in length. The pile test sample was prepared by the following procedure; to decrease the wall friction, grease was thinly coated on the inner wall of the cylinder, and double layers of vinyl sheets (soapy water between them) were attached to the wall. Air-dried sand of water

\footnotetext{
* Department of Construction Engineering
} 


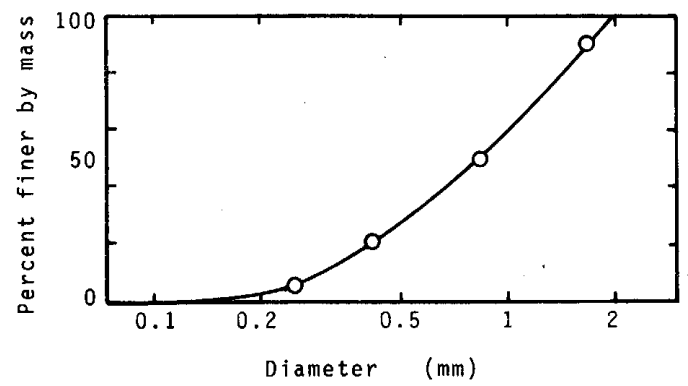

Fig. 1 Particle size distribution of the tested sand.

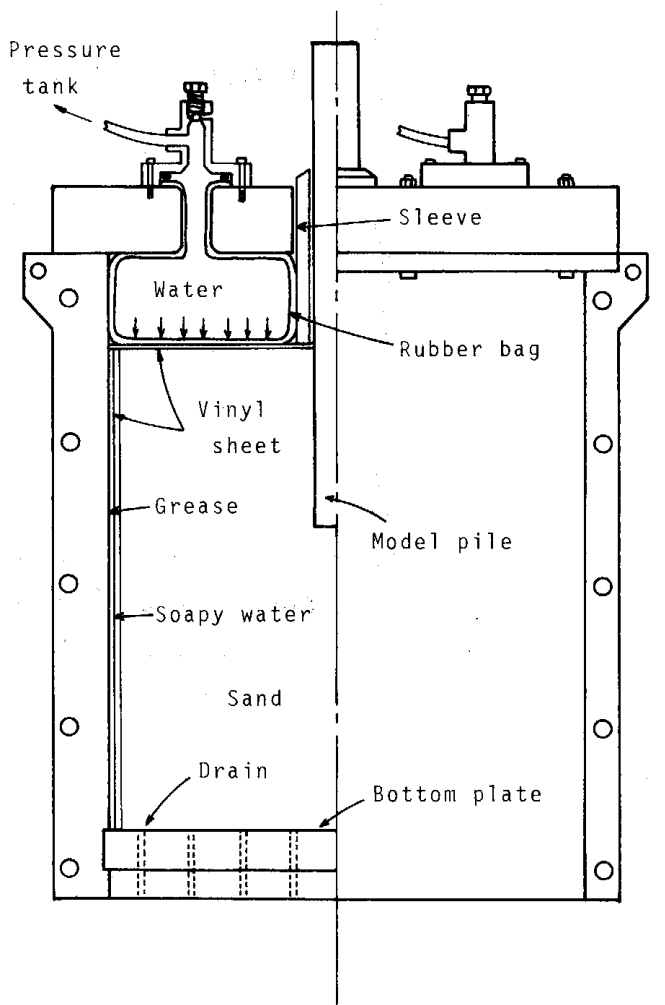

Fig. 2 Sand container for the model pile test.

content of $0.3-0.5$ percent was compacted in $28 \mathrm{~cm}$ thick in a dense state (void ratio of 0.60 , wet density of $1.66 \mathrm{~g} / \mathrm{cm}^{3}$ ) in the sand container, and using a supporting frame the model pile was placed on the sand surface, thence an additional layer of $8 \mathrm{~cm}$ thick sand was filled in. Thus, a $8 \mathrm{~cm}$ deep buried-pile model was prepared. The ceiling plate was set, and as shown in Fig. 2, two rubber bags were inserted through holes for applying the vertical pressure to the sand surface.

\section{(3) Loading test}

For the pile loading test, the sand container was set on the compression machine as shown in Fig. 3. The pile load was increased in controlled steps, with each step being approximately one-twentieth of the contemplated maximum load. At each step, the load was sustained until the rate of settlement became $0.01 \mathrm{~mm} / \mathrm{min}$, and then the incremental load was applied for the next step .

\section{(4) Sampling of sand}

After the loading test, for convenience of sampling, the container sand was wetted with water so that it can stand itself by capillary force, then the sectional sampling was made as follows: a CBR mold with cutter head was placed at the center of the sand container and pushed into the sand as illustrated in Fig. 4(a). The CBR mold was then set in a sample extruder as seen in Fig. 4(b) to sample using thin-wall rings of diameters $10 \mathrm{~cm}, 6 \mathrm{~cm}$ and $4 \mathrm{~cm}$ respectively. The sections for sampling are shown 




Fig. 3 Front view of the loading machine.

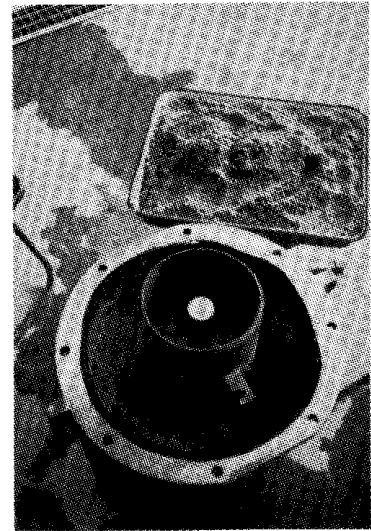

(a)

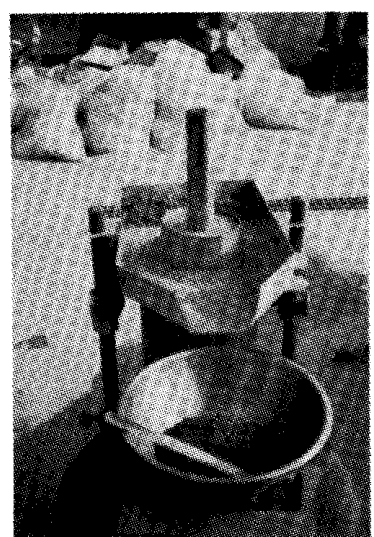

(b)

Fig. 4(a) Sampling of the sand using a CBR mold.

Fig. 4(b) Sectional sampling by thin-wall ring.

in later in Fig. 7. The sample from each section was then dried for 24 hours to measure the specific surface area $S_{w}$.

\section{Experimental Results}

\section{(1) Stress-settlement curve}

Figure 5 depicts the pile stress-settlement curves for three vertical pressures. All the curves continue to slope as the case of actual pile load tests, in other words, there is no general shear failure. It seems that the yielding load $p_{y}$ is not proportional to the magnitude of $\sigma_{v}$. This characteristics of $p_{y} \sim \sigma_{v}$ curve will be discussed later from the viewpoint of particle-crushing of sand around the pile tip.

\section{(2) Particle-crushing distribution}

The value of surface area $S$ of the sample is calculated by $S=S_{w} \times \rho_{d}$, where $\rho_{d}$ indicates the dry density of the sample of each section in the sand container. The value of $S_{w}$ was evaluated by sieving and Blaine method, details of them are given elsewhere ${ }^{4)}$. Unfortunately, the measured value of $\rho_{d}$ was unreliable, then $\rho_{d}$ had to be estimated from the $\rho_{d} \sim S_{w}$ curve determined by the triaxial compression test (Fig. 6).

It is assumed that the value of $S$ determined by the above method represents the value at the center of each section (Fig. 7), and the changes of $S$ in depthwise direction ( $y$-direction) and radial direction ( $x$-direction) were as shown by Fig. 7. This result is for the case of $\sigma_{v}=200 \mathrm{kPa}$ and the final settlement $\delta_{f}=1.8 \mathrm{~cm}$; the broken lines represent either extrapolation or interpolation. The values of $S$ in $x_{-1}$-direction are less than the original value, which suggests that the samples in this direction experienced little particle-crushing, and also that the density of each sample decreased due to the cavitation caused by the penetration of the bulb developing around the pile tip. From the $y \sim S$ and $x \sim S$ curves, the contour lines of equi-amount of particle-crushing around 


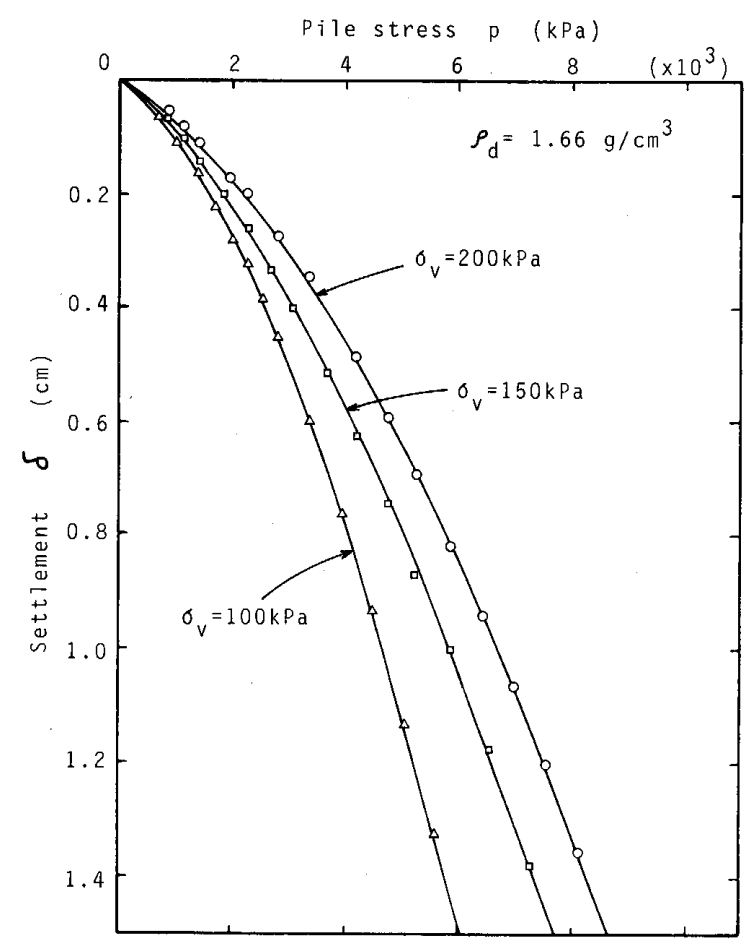

Fig. 5 Pile stress and settlement curve for three vertical pressures.

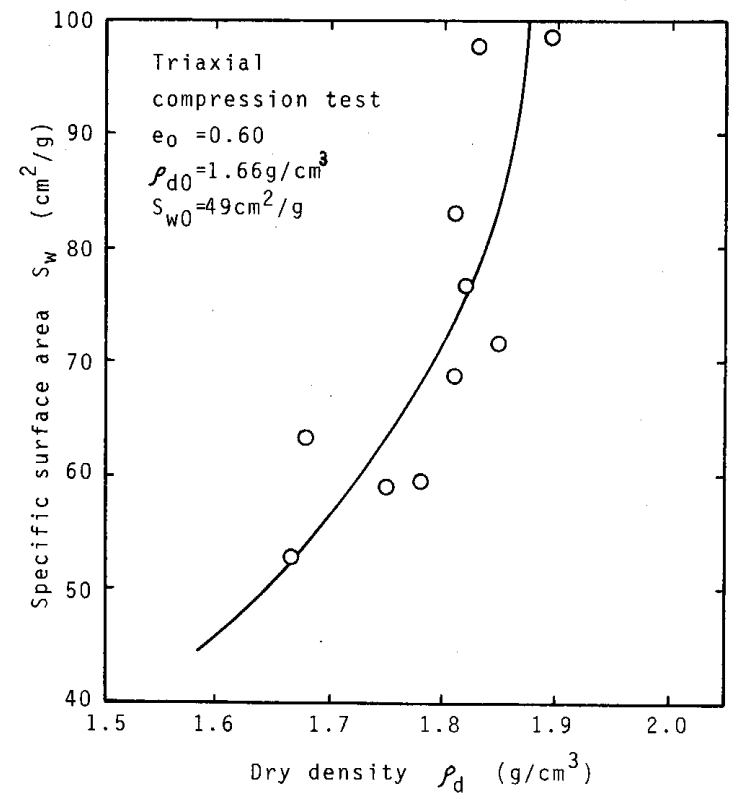

Fig. 6 Relationship between specific surface area $S_{w}$ and dry density $\rho_{d}$ in drained triaxial compression tests.
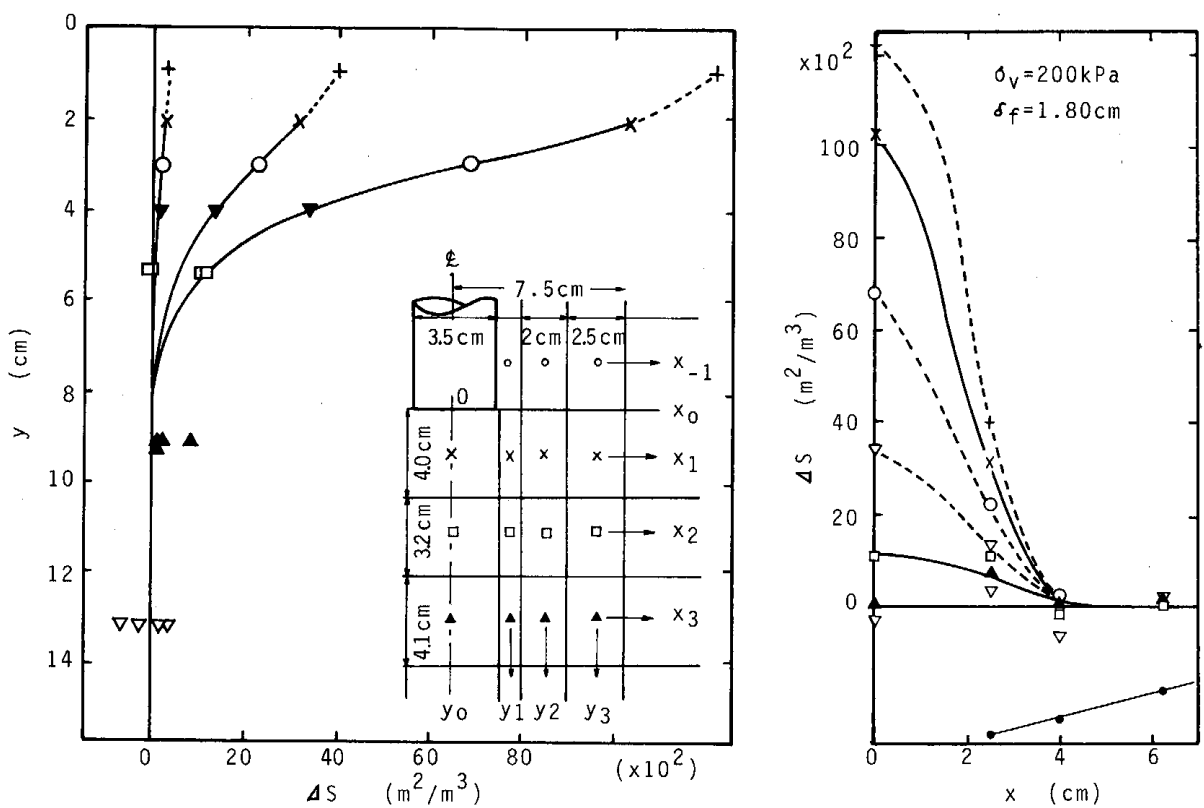

Fig. 7 Changes of $\Delta S$ in depthwise direction (y-direction) and in radial direction (x-direction).

the pile tip can be depicted as shown by Fig. 8. It can be seen that a strongly crushed region of cone shape grows just below the pile, and the surfaces of equi-amount of particle-crushing extend spherically around the cone. 


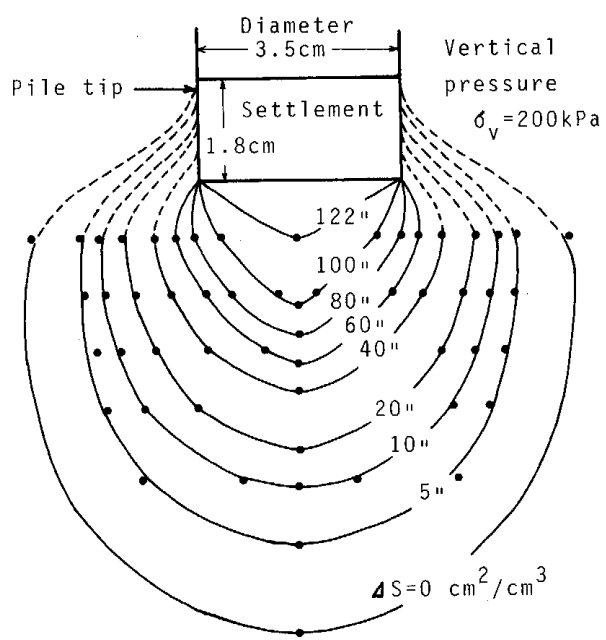

Fig. 8 Contour lines of equi-amount of particle-crushing around the pile tip.

\section{(3) Work dissipated in particle-crushing}

To investigate the mechanism of the point resistance of a pile from the energy balance viewpoint, the work dissipated in particle-crushing at the pile tip was estimated on the basis of $S \sim w$ curve, where $w$ is plastic work done per unit volume $\left(\mathrm{J} / \mathrm{cm}^{3}\right)$. The $S \sim w$ curve was determined by the drained triaxial compression tests under constant confining pressure (Fig. 9). The drained triaxial compression test carried out on a $5 \mathrm{~cm}$ diameter and $12.5 \mathrm{~cm}$ height specimen with a void ratio of 0.61 to 0.65 as being the nearest possible to the void ratio of container sample. Test conditions were; strain rate $=0.2 \% / \mathrm{min}$ and confining pressure $\sigma_{3}=0.5 \mathrm{MPa}$ to $4.0 \mathrm{MPa}$.
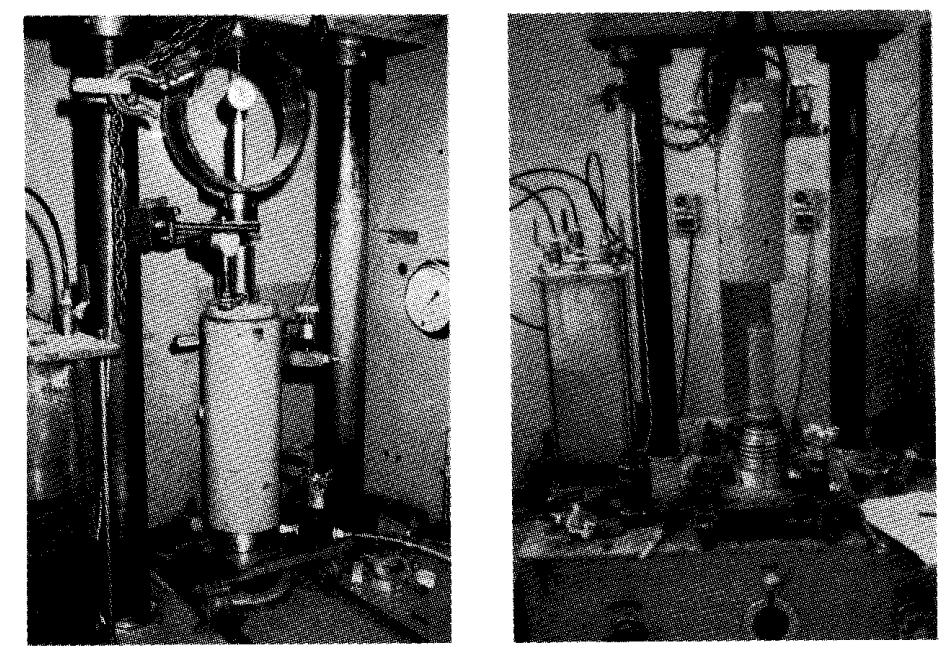

Fig. 9 Drained triaxial compression test on sand specimen.

The stress strain curves obtained are represented in Fig. 10, and the failure envelope appears in Fig. 11. The shear tests were ceased at various strain levels and the samples were taken out from the triaxial chamber to examine the specific surface area $S_{w}$. The dry density $\rho_{d}$ corresponding to the $S_{w}$ value was determined on the 


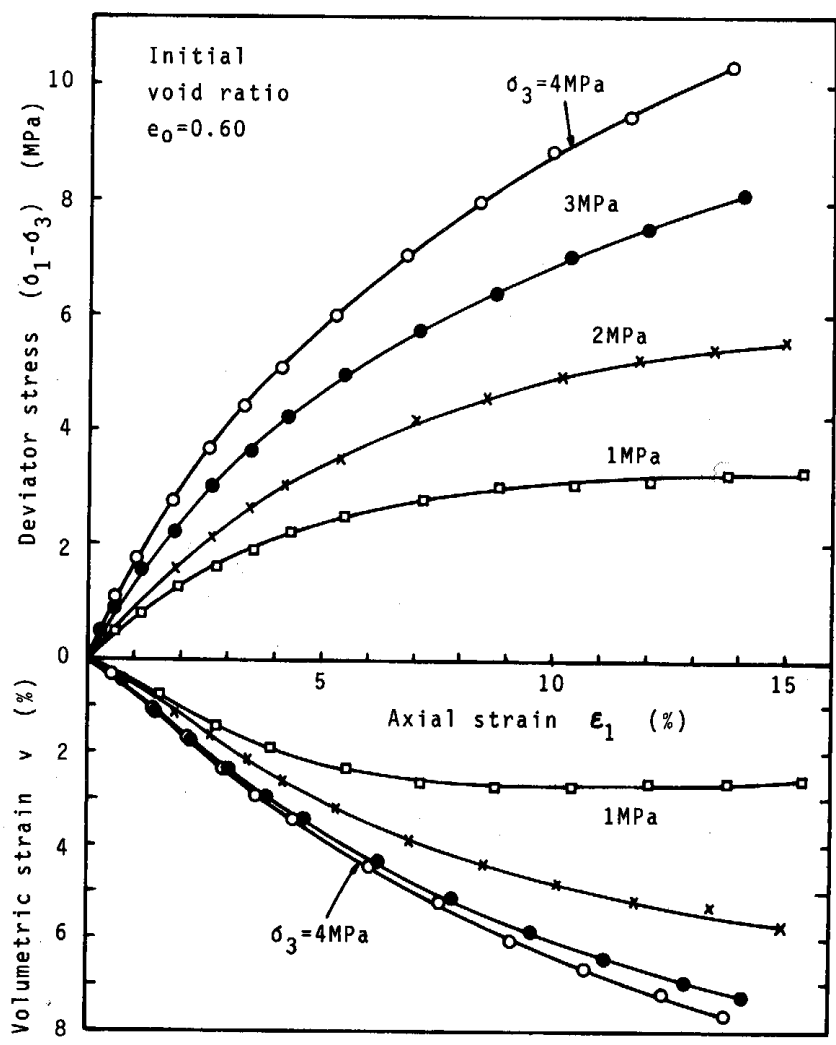

Fig. 10 Stress strain curves in drained triaxial compression test at constant confining pressure.

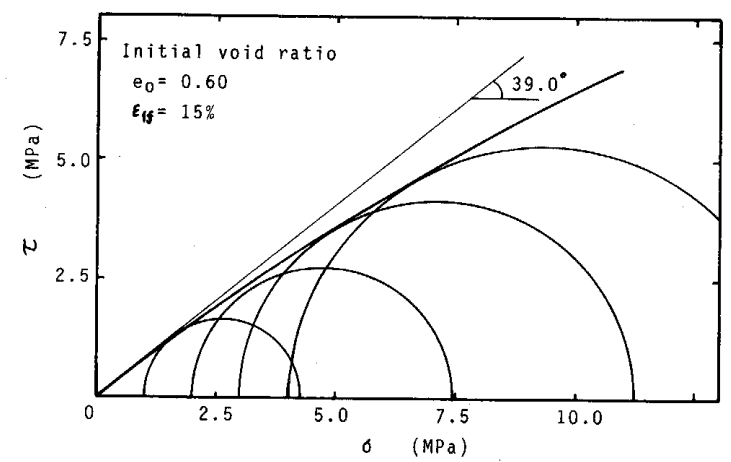

Fig. 11 Failure envelope of the tested sand.

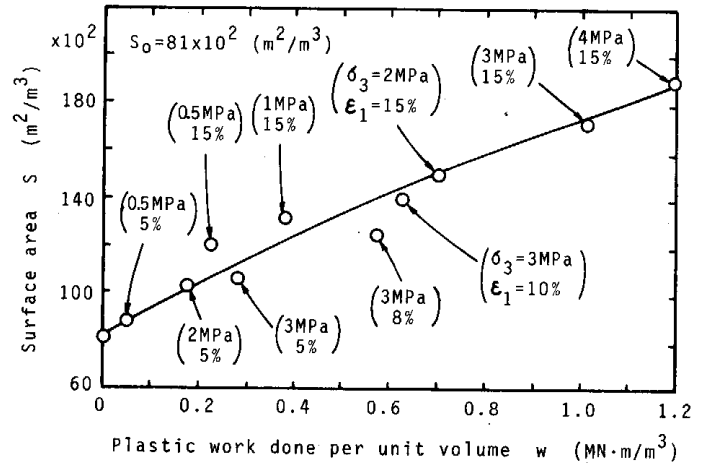

Fig. 12 Relationship between surface area $S$ and plastic work done per unit volume $w$.

basis of the volume change during shear, and with these values the surface areas were calculated from $S=S_{w} \times \rho_{d}$.

The plastic work done per unit volume $w$ is given from the area of the stress strain curve and volumetric strain $v$ as,

$$
w=\int\left(\sigma_{1} d \varepsilon_{1}+2 \sigma_{3} d \varepsilon_{3}\right)
$$




$$
=\int(q d \varepsilon+p d v)
$$

where, $q=\sigma_{1}-\sigma_{3}, p=\left(\sigma_{1}+2 \sigma_{3}\right) / 3, d \varepsilon=d \varepsilon_{1}-(d v / 3)$ and $d v=d \varepsilon_{1}+2 d \varepsilon_{3}$, respectively.

The above equation neglects the elastic component since it occupies only a few percent of the total work.

The author reported that there is a unique relationship between the surface area $S$ and the plastic work done $w$ independent of the stress level and the magnitude of the confining pressure. This is also true for this sample as seen in Fig. 12.

Now, the plastic work done per unit volume $w_{i}$ corresponding to the each value of $\Delta S$ in Fig. 8, can be read on the curve in Fig. 12. The summation of the product of $w_{i}$ and the volume of each section $V_{i}$ in Fig. 8 gives the total work dissipated in the particle-crushing of sand, $W_{c}$, as

$$
W_{c}=\sum w_{i} V_{i}
$$

For the case of Fig. 8, the value of $W_{c}$ becomes $63.7 \mathrm{~J}$.

(4) Work done by the external force

The total work done by the external force $W_{e}$ was evaluated by the enclosed area of the pile stress-settlement curve shown in Fig. 5, and for the case of $\sigma_{v}=200 \mathrm{kPa}$ and $\delta_{f}=1.80 \mathrm{~cm}, W_{e}$ becomes $101.7 \mathrm{~J}$.

A part of the work $W_{e}$ might be dissipated in the frictional work between pile shaft and sand. This frictional work $W_{f}$ was estimated as follows. The horizontal stress acting on the pile shaft $\sigma_{h}$ may be expressed using the Jaky's equation for the coefficient of lateral pressure at rest $K_{0}=1-\sin \phi_{d}$, as,

$$
\sigma_{h}=\sigma_{v} K_{0}
$$

Assuming that the frictional angle between pile and sand is $\phi=2 / 3 \phi_{d}$, then the coefficient of friction is

$$
\mu=\tan \left(2 \phi_{d} / 3\right)
$$

Let the diameter of pile, $D$, buried length $L$ and final settlement $\delta_{f}$, the frictional work $W_{f}$ is

$$
W_{f}=\sigma_{h} \mu \pi D L \delta_{f}
$$

Substituting $D=3.5 \mathrm{~cm}, L=8.0 \mathrm{~cm}, \delta_{f}=1.80 \mathrm{~cm}$ and $\phi_{d}=46.8^{\circ}$ for the case of $\sigma_{v}=200$ $\mathrm{kPa}$, we obtain $W_{f}=5.2 \mathrm{~J}$. Thus the total work done by the vertical force at the pile tip,

$$
W=W_{e}-W_{f}
$$

To this value, the rate of the work dissipated in particle-crushing $W_{c}$ of $63.7 \mathrm{~J}$ occupies a percentage as large as 66 percent. The above-mentioned results clearly indicate that the point resistance of pile in sand greatly depends on the particle-crushing property of the sand. 


\section{Characteristics of Load Settlement Curve}

(1) Mathematical model

Shioi et al. presented a mathematical model for simulating the pile load-settlement curve as follows.

$$
P=P_{\max }\left(1-e^{-\delta / \delta_{s}}\right)
$$

where, $P$ is pile load, $\delta$ is settlement and $\delta_{s}$ is the basic settlement (the settlement corresponding to the yielding load $P_{y}$ ). Eq. (7) is similar to the equation proposed by $\mathrm{C}$. van der Veen ${ }^{7}$.

$$
P=P_{\max }\left(1-e^{-\alpha y}\right)
$$

The regression equation is expressed using an error term $\varepsilon$ as

$$
P=P_{\max }\left(1-e^{-\delta / \delta_{s}}\right)+\varepsilon
$$

The expression for the square difference $S S R$ is,

$$
S S R=\sum \varepsilon_{i}^{2}=\sum\left[P_{i}-P_{\max }\left(1-e^{-\delta_{i} / \delta_{s}}\right)\right]^{2}
$$

Calculation was carried out to find the value of $P_{\max }$ and $\delta_{s}$ to minimize $S S R$. The reliability of the model to the experimental curve was evaluated by,

$$
V V=\frac{1}{P_{\max }} \sqrt{\frac{S S R}{n-2}}
$$

Yielding load of pile $P_{y}$ is defined by

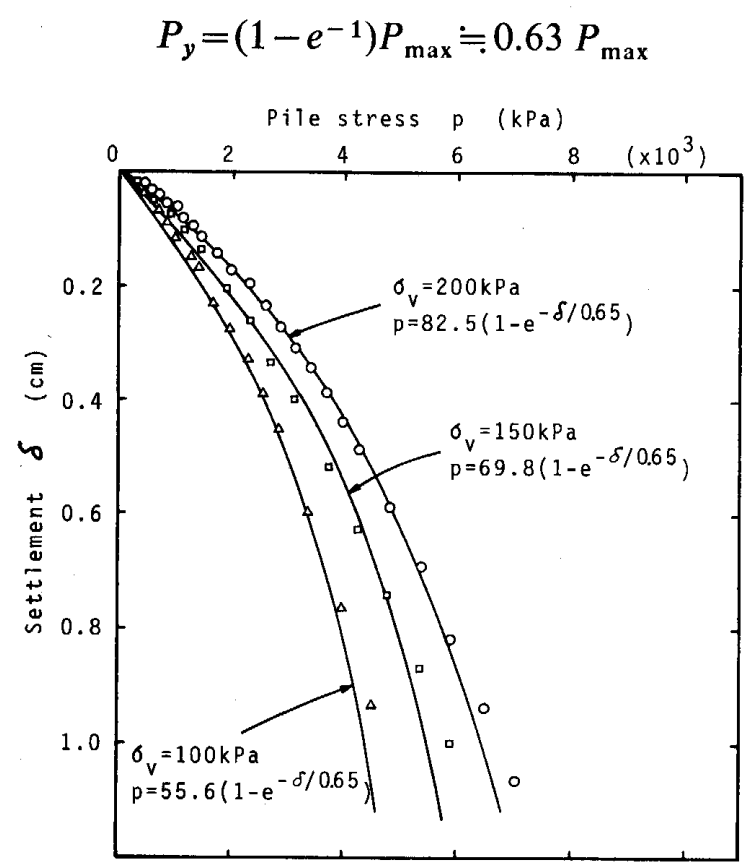

Fig. 13 Analytical curve of pile stress and settlement compared with the experimental curve. 
(2) Result of analysis

The result of analysis in Fig. 13 shows that the curve of the Eq. (7) well agrees with the experimental curve. Calculated values of $p_{y}, p_{\max }$ and $\delta_{s}$ are summarized in Table 1. The Eq. (7) have proved to be applicable to the practical pile load-settlement curve, hence it can be said that the present model pile curve fairly represents the practical pile behavior in sand.

Table 1. Calculated values of $p_{y}, p_{\max }$ and $\delta_{s}$.

\begin{tabular}{ccccccrc}
\hline \hline Test No. & $\begin{array}{c}\sigma_{v} \\
(\mathrm{kPa})\end{array}$ & $\begin{array}{c}\delta_{f} \\
(\mathrm{~cm})\end{array}$ & $\begin{array}{c}\delta_{s} \\
(\mathrm{~cm})\end{array}$ & $\begin{array}{c}p_{y} \\
(\mathrm{kPa})\end{array}$ & $\begin{array}{c}p_{\max } \\
(\mathrm{kPa})\end{array}$ & \begin{tabular}{c}
\multicolumn{1}{c}{$S S R$} \\
$(\mathrm{kPa})^{2}$
\end{tabular} & $V V$ \\
\hline 505 & 100 & 1.98 & 1.30 & 5670 & 9000 & 177050 & 0.027 \\
507 & 150 & 0.52 & 0.50 & 4100 & 6500 & 19660 & 0.012 \\
508 & 150 & 1.81 & 1.40 & 7560 & 12000 & 127250 & 0.017 \\
506 & 200 & 1.80 & 1.20 & 7560 & 12000 & 219740 & 0.023 \\
\hline
\end{tabular}

\section{Discussions}

The relationship between the ultimate bearing capacity $p_{\max }$ and the vertical pressure $\sigma_{v}$ is depicted in Fig. 14 using the values described in Table 1. This curve shows that $p_{\max }$ is not proportional to the magnitude of $\sigma_{v}$ that is known as a characteristic of the practical pile. On the other hand, the conventional equation for the point resistance of a pile in sand is expressed as

$$
P_{\max }=\sigma_{v} N_{q}
$$

where $N_{q}$ is the coefficient of bearing capacity. Equation (13) leads to a consequence that the value of $p_{y}$ is proportional to the magnitude of the vertical pressure. However, this is not true for the characteristic of the practical $P_{y} \sim \sigma_{v}$ curve.

In the previous paper, the authors proposed a method for evaluating the $P_{\max } \sim \sigma_{v}$ relationship based on the high pressure triaxial compression tests ${ }^{4}$. The $P_{\max } \sim \sigma_{v}$ curve for the present sample obtained by applying the same method is compared with the curve shown in Fig. 13.

The $\phi_{d} \sim \sigma_{1 f}$ curve shown in Fig. 15 depicts the triaxial compression tests on sand where $\sigma_{1 f}$ is the major principal stress at failure. Here $\sigma_{1 f}$ is assumed to be the same as the yielding stress of the pile, i.e., $\sigma_{1 f}=P_{\max } / A_{p}$. Substituting this $P_{\max }$ into Eq. (12), the yielding load $P_{\boldsymbol{y}}$ may be estimated by,

$$
P_{y}=0.63 \sigma_{1 f} A_{p}
$$

Now, among a number of $N_{q} \sim \phi_{d}$ curves proposed, the Vesić's curve ${ }^{9)}$ can be formulated as,

$$
\log N_{q}=0.07425\left(\phi_{d}-30\right)+1.415
$$

Combining the above equation with the $\phi_{d} \sim \sigma_{1 f}$ curve, the $N_{q} \sim P_{\max }$ relationship is 




Fig. 14 Relationship between ultimate bearing capacity of pile and vertical pressure.

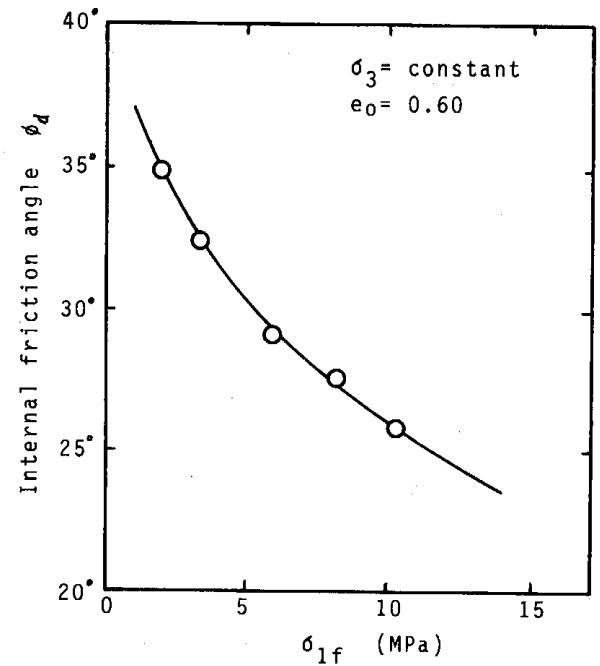

Fig. 15 Relationship between internal friction angle $\phi_{d}$ and major principal stress at failure $\sigma_{1 f}$.

obtained, from which we can depict $p_{\max } \sim \sigma_{v}$ curve as shown in Fig. 14. In this figure, the experimental curve of Fig. 13 is also drawn for comparison. The similarity of the two curves indicates that the method of estimation of $p_{\max } \sim \sigma_{v}$ based on the triaxial compression test is appoximately reasonable.

\section{Conclusions}

For making clear the mechanism of the point resistance of pile in sand, especially from a particle-crushing viewpoint, a series of model pile tests were carried out from which the following conclusions were obtained.

(1) At the tip of model pile, a bulb-shaped particle-crushing zone develops in a dimension of about twice the diameter of the pile.

(2) The work dissipated in the particle-crushing of sand is as large as 66 percent of the total work done by the external force at the pile tip.

(3) The point resistance of a pile in sand greatly depends on the particle-crushing property of the sand.

(4) Pile stress-settlement curve can be simulated reasonably by a mathematical model proposed by Shioi et al..

(5) Relationship between point resistance and vertical pressure of a pile can be predicted from the triaxial compression tests in a particle-crushing region.

\section{References}

1) BCP committee, "Study on the bearing capacity of piles in sand," (1969) (in Japanese).

2) Tono, I. and Yoshimi, Y., "On the particle-crushing of soil at the pile tip caused by the penetration of the pile," 5th Annual Meeting on SM \& FE, pp. 193-196 (1970) (in Japanese).

3) Takano, A. Kishida, H. and Saeki, E., "Load settlement characteristics of piles buried in 
sand," 9th Annual Meeting on SM \& FE, pp. 533-535 (1974) (in Japanese).

4) Miura, N. and Yamanouchi, T., "Effect of particle-crushing on the shear characteristics of a sand," Proc JSCE, No. 260, pp. 109-118 (1977) (in Japanese).

5) Shioi, Y. et al., "A method for evaluating the bearing capacity of piles by non-linear regression analysis of load settlement curve," 23rd Symposium on SM \& FE, pp. 9-16 (1978) (in Japanese).

6) Asanuma, H. et al., "Pattern classification of the $p \sim s$ curve of pile," 17th Annual Meeting on SM \& FE, pp. 522-525 (1982) (in Japanese).

7) van der Veen, C., "The bearing capacity of a pile," Proc. of the 3rd Int. Conf. SM \& FE, 2, pp. 84-90 (1953).

8) Institute of the Ministry Construction, "Data of the vertical loading tests of piles," Report of the Institute of the Ministry of Construction (1980) (in Japanese).

9) Vesić, A. S., "Ultimate loads and settlements of deep foundation in sand," Bearing Capacity and Settlement of Foundations, Duke Univ., North Carolina, pp. 53-68 (1967). 